\title{
Loss of Consciousness at Onset of Subarachnoid Hemorrhage as Marker of Short Term Outcome
}

\author{
Rahat Amin Chowdhury ${ }^{1}$ Md. Habibur Rahman², ATM Hashibul Hasan', \\ Iftikher Alam4, Mansur Habib

\begin{abstract}
${ }^{1}$ Assistant Professor, Department of Neurology, Sylhet Women's Medical College, Sylhet, Bangladesh; ${ }^{2}$ Assistant Professor, Department of Neurology, National Institute of Neurosciences and Hospital, Dhaka, Bangladesh; ${ }^{3}$ Assistant Professor, Department of Neurology, National Institute of Neurosciences and Hospital, Dhaka, Bangladesh; ${ }^{4}$ Assistant Professor, Department of Neurology, Dhaka Medical College, Dhaka, Bangladesh; ${ }^{5}$ Professor, Department of Neurology, Dhaka Medical College, Dhaka, Bangladesh
\end{abstract}

[Received on: 22 November 2020; Accepted on: 12 December 2020; Published: 1 January 2021]

\begin{abstract}
Background: Studies assessing the impact of loss of consciousness (LOC) on prognosis of subarachnoid hemorrhage (SAH) has been limited. Objective: This scientific assessment was done to determine the effect of LOC on outcome of SAH. Methodology: This hospital based observational study was done in Department of Neurology of Dhaka Medical College Hospital, Dhaka, Bangladesh from January 2018 to December 2018. Patients with the diagnosis of SAH admitted in the in-patient wards of Neurology, Neurosurgery and Internal Medicine were taken as study population. The patients were divided in two groups with either presence (B) or absence of loss of consciousness (A). Group B was further subdivided into 3 subgroup depending admission WFNS scale grades (BI= WFNS II \&III, BII=WFNS IV and BIII=WFNS V). Follow up was done in the stroke clinic, outpatient department of Neurology or by telephone interviews of patients, caregivers or family members. Outcome was measured by modified Rankin Scale (mRS). Result: A total of 75 patients were divided into group A and Group B. Six (8.0\%) patients died during hospital stay, 6 died after 3 months. All those died during hospital stay were from group B. At 3 months, 16(21.3\%) patients were lost during follow up. In group A at discharge $28.6 \%$ patients had poor outcome whereas $36 \%$ of patients in group B had poor outcome. Within group B most of the patients having poor outcome were in subgroup BIII $(75.0 \%)$ compared to $33.0 \%$ cases in BI $(p=0.023)$. About $16.7 \%$ cases in group A had poor outcome at 3 months and $75.0 \%$ cases in Group BIII. Furthermore, 8.3\% patients died in Group A, however, 25.0\% died in Group BIII. WFNS grade (IV or V) had statistically significant influence on poor outcome among patients having LOC (adjusted Odds ratio is 2.20, $\mathrm{p}=0.04$ and $95 \%$ CI 1.03-4.71). Conclusion: Loss of consciousness at onset of SAH is an important marker for poor outcome. [Journal of National Institute of Neurosciences Bangladesh, January 2021;7(1): 20-24]
\end{abstract}

Keywords: Loss of Consciousness; Subarachnoid Hemorrhage; Outcome

Correspondence: Dr. Rahat Amin Chowdhury, Assistant Professor, Department of Neurology, Sylhet Women's Medical College, Sylhet, Bangladesh; Cell no.: +8801711306150; Email: dr.rahat014@yahoo.com

Conflict of interest: None

Funding agency: This research project was not funded by any group or any institution.

Contribution to authors: Dr. Rahat Amin Chowdhury conceptualized the study and was also involved in writing the manuscript along with the data collection process. Dr. Md. Habibur Rahman was involved in setting the methodology and analyzing the data. Dr. ATM Hasibul Hasan was involved in data collection and partly writing and editing the manuscript. The rest of the authors supervised the study procedure and also was involved in editing the manuscript.

How to cite this article: Chowdhury RA, Rahman MH, Hasan ATMH, Alam I, Habib M. Loss of Consciousness at Onset of Subarachnoid Hemorrhage as an Important Marker of Short Term Outcome. J Natl Inst Neurosci Bangladesh, 2021;7(1):20-24 Copyright: (C2021. Chowdhury et al. Published by Journal of National Institute of Neurosciences Bangladesh. This article is published under the Creative Commons CC BY-NC License (https://creativecommons.org/licenses/by-nc/4.0/). This license permits use, distribution and reproduction in any medium, provided the original work is properly cited, and is not used for commercial purposes.

\section{Introduction}

Subarachnoid hemorrhage is often accompanied by a dramatic increase in intracranial pressure and reduction in cerebral perfusion pressure, leading to transient cessation of cerebral blood flow, as documented by angiography and transcranial Doppler ultrasonography ${ }^{1-4}$.
Loss of consciousness at ictus also has been linked to global cerebral edema, a marker of early brain injury after SAH demonstrated on computed tomographic (CT) scan $^{5}$. Initial clinical grade assessed with the Hunt and Hess scale or World Federation of Neurosurgeons scale are well established strong prognostic indicators in 
$\mathrm{SAH}^{6}$. There are data analyzing the long-term effect of symptoms at onset of SAH on survival and recovery.

The most common mechanisms underlying LOC at onset of SAH are likely to be reduced cerebral perfusion pressure in the setting of elevated intracranial pressure, seizures, or neurogenic cardiopulmonary dysfunction, manifesting as hypotension or frank cardiac arrest. It is well established that even with transient LOC, a corresponding episode of brief global hypoxia-ischemia is enough to trigger apoptosis, delayed neuronal death, and other negative downstream effects in selectively vulnerable cell populations ${ }^{6,7}$.

With improvements in therapy for vasospasm and safer surgical techniques for aneurysm repair, early brain injury now poses the most important threat to survival with good recovery after $\mathrm{SAH}^{8}$. Studies assessing the impact of LOC on prognosis of SAH has been limited. In a resource constrained country such as Bangladesh the condition is predictably worse. A scientific analysis of effect of initial loss of consciousness on outcome of SAH may be helpful to assess the prognosis of patients and planning appropriate counseling in the future.

\section{Methodology}

This was a hospital based observational study conducted in the Department of Neurology at Dhaka Medical College Hospital, Dhaka, Bangladesh from July 2015 to June 2017 for a period of two years. Patients with diagnosis of SAH who were admitted in the in-patient wards of Neurology, Neurosurgery and Internal Medicine were taken as study population. They were subsequently followed up in the stroke clinic, outpatient department of Neurology or by telephone interviews of patient, caregivers or family members. Inclusion criteria were patients aged 18 years or more including both sexes, clinical features and radiologic evidence (CT scan of head) suggestive of SAH, follow up after 3 months or patient dies within this time. Exclusion criteria were patients with traumatic SAH, where initial level of consciousness not known, patient undergoing surgical or endovascular intervention. A structured questionnaire was filled up as well as demographic data including age, sex and relevant medical history. History of present illness, including symptoms suggestive of SAH e.g. headache, LOC, nausea, vomiting, change in mental status, seizures etc. Any feature of sentinel headache were obtained by interview of the patient, family members and emergency medical officers who attended the patient if possible. Seizure attacks were recorded based on accounts from eyewitnesses. Co-morbid medical history of hypertension, diabetes, dyslipidemia, ischemic heart disease and family history of SAH were also recorded. Results from the initial neurologic examination on hospital admission were evaluated by the Glasgow Coma Scale administered by emergency department health care professionals or in house residents who received the patients. Patients were grouped in the following way. World Federation of Neurosurgical societies (WFNS) SAH scoring along with LOC was considered for categorization of the patients. Group A included patients of SAH without initial LOC (WFNS SAH score grade I) and those with initial LOC were designated in Group B. The Group B patients were further sub grouped according to the WFNS grade. BI was labeled for WFNS grade II and III, BII for WFNS grade IV, BIII for WFNS grade V. Patients were treated according to the local protocol with standard conservative management. Patients were followed up first within 24 hours of hospital admission. Second follow up was at the time of discharge. Modified Rankin Scale (mRS) scores were prospectively assessed at 3 months. Poor outcome was defined by mRS 4 or more. Hospital complications after SAH were diagnosed and treated by the treating physician. Multivariable logistic regression analysis was used to adjust factors for poor outcome other than initial LOC, such as age, hypertension (HTN), diabetes mellitus (DM), sex, WFNS grade. Ethical approval was taken from Ethical Review Committee in Dhaka Medical College. After collection of all data these were checked and edited. Then data was entered into the computer with the help of software SPSS for windows programme version 22.0. Results on continuous measurements were presented on mean \pm SD- Standard deviation (min-max) and results on categorical measurements was presented in number (\%). Association of loss of consciousness with outcome after subarachnoid hemorrhage was evaluated with Chi-square test. Independent sample $t$ test was used to compare between two groups. Multivariate logistic regression analysis was done to measure the effect of loss of consciousness on outcome. Significance was assessed at $5 \%$ level of significance.

\section{Results}

A total of 75 patients were enrolled in two groups in this study. Mean age of patients enrolled in this study was $55.67 \pm 0.374$ ranging from $25-80$ years. Mean age of male patients was $56.50 \pm 10.707$ ranging from 23 to 80 years and that of female was $54.34 \pm 19.39$ and 25 to 72 years (Table 1$)$. 
Table 1: Distribution of Respondents by Age $(n=75)$

\begin{tabular}{lccc}
\hline Respondents & Range & Mean \pm SD & P value \\
\hline All $(\mathrm{n}=75)$ & $25-80$ & $55.67 \pm 10.34$ & \\
Male $(\mathrm{n}=46)$ & $23-80$ & $56.50 \pm 10.707$ & $0.374^{*}$ \\
Female $(\mathrm{n}=29)$ & $25-72$ & $54.34 \pm 19.39$ & \\
\hline
\end{tabular}

There was no statistically significant difference of age and sex between the groups $(\mathrm{p}>0.05)$. Risk factors assessed were hypertension, diabetes mellitus, arrhythmia, smoking, family history of subarachnoid hemorrhage (Table 2).

Table 2: Risk factors among two groups $(n=75)$

\begin{tabular}{lccc}
\hline Risk factors & \multicolumn{2}{c}{ Loss of consciousness(LOC) } & P Value \\
\cline { 2 - 3 } & Present(n=61) & Absent(n=14) & \\
\hline Hypertension & $38(62.30 \%)$ & $5(28.40 \%)$ & $0.023^{* *}$ \\
Diabetes mellitus & $15(24.60 \%)$ & $2(14.30 \%)$ & $0.330^{*}$ \\
Smoking & $25(41.00 \%)$ & $5(35.70 \%)$ & $0.481^{*}$ \\
Arrhythmia & $6(9.80 \%)$ & $0(0 \%)$ & $0.276^{*}$ \\
FHSH & $4(6.60 \%)$ & $0(0 \%)$ & $0.429^{*}$ \\
\hline
\end{tabular}

FHSH: Family history of subarachnoid hemorrhage; Chi-square test was done to analyze the data.

It was observed that in both the group most frequent risk factor was hypertension $(62.30 \%$ and $28.40 \%)$ followed by smoking and diabetes mellitus respectively. But there was no significant $(\mathrm{p}>0.05)$ difference of risk factors between the groups except that of hypertension $(\mathrm{p}<0.05)$.

Headache is the most frequent presenting symptoms among two groups $(83.6 \%$ and $92.9 \%)$ followed by vomiting and sentinel headache. No patient in group A (Loss of consciousness absent) had tonic-clonic activity. There is no statistically significant difference of frequency of symptoms among the groups except tonic-clonic activity $(\mathrm{p}<0.05)$ (Table 3$)$.

Table 3: Distribution of presenting symptoms among two groups of patients $(n=75)$

\begin{tabular}{lccc}
\hline Presenting & \multicolumn{2}{c}{ Loss of consciousness (LOC) } & P Value \\
\cline { 2 - 4 } Symptoms & Present(n=61) & Absent(n=14) & \\
\hline Headache & $51(83.6 \%)$ & $13(92.9 \%)$ & $0.343^{*}$ \\
Vomiting & $34(55.7 \%)$ & $9(64.3 \%)$ & $0.392^{*}$ \\
Tonic-clonic activity $14(23.0 \%)$ & $0(0 \%)$ & $0.040^{* *}$ \\
Sentinel headache & $15(24.6)$ & $2(14.3 \%)$ & $0.330^{*}$ \\
\hline
\end{tabular}

Chi-square test was done to analyze the data.

The most frequent complication among the hospitalized patients were delayed neurological deficit $(34.4 \%$ \& $7.1 \%)$ followed by delayed cerebral ischemia $(31.1 \%$ \&
$7.1 \%)$ and rebleeding $(24.6 \% \& 0 \%)$ (Table 4).

Table 4: Distribution of complications among the groups $(\mathrm{n}=75)$

\begin{tabular}{lccc}
\hline Complication & \multicolumn{2}{c}{ Loss of consciousness(LOC) } & P Value \\
\cline { 2 - 3 } & Present(n=61) & Absent(n=14) & \\
\hline $\begin{array}{l}\text { Delayed neurological } \\
\text { deficit }\end{array}$ & $21(34.4 \%)$ & $1(7.1 \%)$ & $0.037^{* *}$ \\
$\begin{array}{l}\text { Delayed cerebral } \\
\text { ischemia }\end{array}$ & $19(31.1 \%)$ & $1(7.1 \%)$ & $0.060^{*}$ \\
Rebleeding & $15(24.6 \%)$ & $0(0 \%)$ & $0.031^{* *}$ \\
\hline
\end{tabular}

Chi-square test was done to analyze the data.

Statistically significant difference of complications among the group was observed for delayed neurological deficit and rebleeding $(p<0.05)$ but not for that of delayed cerebral ischemia $(\mathrm{p}>0.05)$. Outcome was measured by modified Rankin Scale in two groups. It was observed that $71.4 \%$ of patients in group A had good outcome (mRS=1-3) but it was $25.0 \%$ in group BIII. No patient in group A died during hospital admission but 6 patients died in group B. There is statistically significant difference of outcome (good) at discharge between the groups $(\mathrm{p}<0.05)$ (Table 5).

Table 5: Distribution of outcome of patients at discharge among the groups $(\mathrm{n}=75)$

\begin{tabular}{lccc}
\hline Group & \multicolumn{2}{c}{ Outcome at discharge } & P Value \\
\cline { 2 - 3 } Good & Poor & \\
\hline Group-A (WFNS-I, n=14) & $10(71.4 \%)$ & $4(28.6 \%)$ & \\
Group-B (WFNS:II-V, n=61) & & \\
BI (WFNS-II\&III, n=27) & $18(66.7 \%)$ & $9(33.3 \%)$ & $0.023 * *$ \\
BII (WFNS-IV, n=18) & $8(44.4 \%)$ & $10(55.6 \%)$ & \\
BIII (WFNS-V, n=16) & $4(25 \%)$ & $8(75 \%)$ & \\
\hline
\end{tabular}

Chi-square test was used to analyze the data; Good outcome $=m R S$ 1-3; Poor Outcome $=m R S$ 4- 5

Analysis of outcome after 3 months showed that 16.7\% in group A had poor outcome at 3 months but it was $75.0 \%$ in Group BIII. About $8.3 \%$ patients died in Group A, but $25 \%$ died in Group BIII. There was statistically significant $(\mathrm{p}<0.05)$ difference of poor outcome between the groups (Table 6).

Table 7 shows the effect of different admission characteristics of patient on poor outcome (mRS:4-6) compared with good outcome (mRS:1-3) after 3 months of discharge. Comparison was carried out between HTN, DM and sex. For WFNS comparison was between grade 1 with grade IV or V. It was observed that there was no overall statistically 
significant effect of admission characteristics on poor outcome except for WFNS-IV or V $(\mathrm{p}<0.05)$. AOR for WFNS IV or $\mathrm{V}$ was 2.20. It means that if a patient had World Federation of Neurosurgical Societies grading scale grade IV or $\mathrm{V}$, he/she had 2.20 times the risk of having poor outcome than for World Federation of Neurosurgical Societies grading scale grade I.

Table 6: Distribution of Outcome after 3 Months Among Two Groups $(\mathrm{n}=59)$

\begin{tabular}{lcccc}
\hline Group & \multicolumn{3}{c}{ Outcome at 3 months } & P Value \\
\cline { 2 - 3 } & Good & Poor & Dead & \\
\hline Group A (WFNS-I, $\mathrm{n}=12)$ & $9(75.0 \%)$ & $2(16.7 \%)$ & $1(8.3 \%)$ & \\
Group B (WFNS-II-V, $\mathrm{n}=47)$ & & & \\
BI (WFNS-II-III, $\mathrm{n}=22)$ & $7(31.8 \%)$ & $14(63.6 \%)$ & $1(4.5 \%)$ & $0.007 * *$ \\
BII (WFNS-IV, $\mathrm{n}=13)$ & $5(38.4 \%)$ & $7(53.8 \%)$ & $1(7.6 \%)$ & \\
BIII (WFNS-V, $\mathrm{n}=12)$ & $0(0 \%)$ & $9(75.0 \%)$ & $3(25 \%)$ & \\
\hline
\end{tabular}

Chi-square test was used to analyze the data; Good outcome $=\mathrm{mRS} 1-3$; Poor Outcome $=\mathrm{mRS} 4-5$

Table 7: Multivariable admission predictor of poor outcome after 3 months.

\begin{tabular}{lccc}
\hline Variable & p- value & AOR & $\mathbf{9 5 \%}$ CI Of AOR \\
\hline Intercept & $0.476^{*}$ & & \\
Age & $0.478^{*}$ & 0.978 & $0.919-1.040$ \\
HTN & $0.666^{*}$ & 1.319 & $0.375-4.637$ \\
DM & $0.588^{*}$ & 1.640 & $0.274-9.813$ \\
Sex & $0.690^{*}$ & 1.295 & $0.364-4.615$ \\
WFNS (IV or V) & $0.04^{* *}$ & 2.20 & $1.03-4.71$ \\
\hline
\end{tabular}

Multinomial logistic regression analysis was done to analyze the data; AOR-adjusted Odds ratio, SE-standard error, CI-confidence interval HTN-hypertension, DM-diabetes mellitus, WFNS-World Federation of Neurosurgical Societies grading scale; WFNS-World Federation of Neurosurgical Societies grading scale; **Statistically significant;*Statistically non-significant

\section{Discussion}

In this study the relationship between the loss of consciousness at admission and short term outcome of SAH patients was sought. This study revealed the significance of LOC at presentation with in hospital mortality and short term outcome among these patients. Majority of patients were relatively older (45 to 65 years) which corresponds with similar studies conducted by Suarez et $\mathrm{al}^{9}$ and Suwatcharangkoon et $\mathrm{al}^{10}$. Similar to this study, Hassan et $\mathrm{al}^{11}$ and Islam et $\mathrm{al}^{12}$ found higher incidence among male $(60.0 \% \& 59.8 \%)$. In line with the findings of Hassan et $\mathrm{al}^{11}$ Islam et $\mathrm{al}^{12}$ and Linn et $\mathrm{al}^{13}$ sudden headache and vomiting were the most frequent presenting symptom in this study. But vomiting is not a distinctive feature as almost half the patients with non-hemorrhagic thunderclap headache also report vomiting at onset. The frequency of convulsion was three times higher than those reported by Al-Shahir et $\mathrm{a}{ }^{14}$ Similar to the report of Leonardo et a ${ }^{15}$ sentinel headache was not uncommon in this study. The reported frequency of LOC as a presenting symptoms was much higher in this study than the report of Suwatcharangkoon et $\mathrm{a}^{10}$, Hassan et $\mathrm{al}^{11}$ and Al-Shahi et $\mathrm{al}^{14}$. This is probably due to the difference in operational definitions among these studies. Delayed neurological deficit, delayed cerebral ischemia and re-bleed were the most frequent in hospital neurological complication observed in this study. Rashid et $\mathrm{al}^{16}$ reported similar observation from Kashmir, India.

The distribution of risk factors for SAH were also assessed in this study. In comparison to the report of Koshy et $\mathrm{al}^{17}$, who searched for risk factors of SAH in Indian population; hypertension and smoking were more frequent in this study. But Hassan et $\mathrm{al}^{11}$ also observed findings similar to this study.

There was no significant difference between group A and group B in terms presenting symptoms, except for seizure activity $(p=0.04)$ which was present only in group B. This was in contrast to the findings of Suwatcharangkoon et a $\mathrm{l}^{10}$ for reasons unexplained.

There was also statistically significant difference of having complication between the groups rebreeding $(\mathrm{p}=0.031)$ and delayed neurological deficit $(\mathrm{p}=0.037)$. Suwatcharangkoon et $\mathrm{al}^{10}$ found that all types of neurological complication was significantly $(p<0.001)$ more common in patients of subarachnoid hemorrhage with loss of consciousness.

Subarachnoid hemorrhage is serious disease with high morbidity and mortality. A thirty days case fatality has ranged from $8.0 \%$ to $67.0 \%$ in different studies ${ }^{18,19}$. In present study $6(8.0 \%)$ patient died during hospital stay, another 6 patient died within 3 month. Apparent low mortality might be explained by avoidance of health care service with severely ill patients or they might be dead before reaching hospital. In present study outcome of patients at discharge and after 3 month were measured by using modified Rankin's scale (mRS). Statistically significant difference of poor outcome was observed between group $\mathrm{A}$ and $\mathrm{B}$ $(p=0.023)$. Moreover, subgroup analysis also revealed that the outcome was worst for group B-III. There was statistically significant $(\mathrm{p}=0.007)$ difference of poor outcome between the subgroups. Outcome analysis from different studies yielded similar results. ${ }^{10,20,21} \mathrm{~A}$ 
multivariable logistic regression analysis was carried out to determine the magnitude of admission characteristics (age, sex, HTN, DM, WFNS grade) of patients on outcome after 3 months of SAH. Patients having LOC only WFNS grade (IV or V) have statistically significant influence on poor outcome. Suwatcharangkoon et $\mathrm{al}^{10}$ also reported similar observation.

\section{Conclusion}

SAH patients presenting with LOC have higher in hospital mortality and poorer secondary functional outcome at three months. Moreover, the outcome is worse in patients of WFNS grade III and IV and presenting with LOC. So, LOC at onset of subarachnoid hemorrhage may serve as an important marker for poor outcome at discharge and 3 months after the event.

Acknowledgement: We are really grateful to the department of Neurology, Neurosurgery and Internal medicine of Dhaka Medical College \& Hospital for extending their full support and co-operation during the study.

\section{References}

1. Altay T, Smithason S, Volokh N et al. A novel method for subarachnoid hemorrhage to induce vasospasm in mice. J. Neurosci. Methods 2009; 183: 136-140.

2. Komotar RJ, Schmidt JM, Starke RM, et al. Resuscitation and critical care of poor-grade subarachnoid hemorrhage. Neurosurgery 2009; 64:397-410.

3. Leclerk JL, Garcia JM, Diller MA et al. A Comparison of Pathophysiology in Humans and Rodent Models of Subarachnoid Hemorrhage. Front. Mol. Neurosci. 22 March 2018.

4. Hayashi T, Suzuki A, Hatazawa J. Cerebral circulation and metabolism in the acute stage of subarachnoid hemorrhage. J Neurosurg, 2000; 93:1014-18

5. Claassen J, Carhuapoma JR, Kreiter KT, Du EY, Connolly ES, Mayer SA. Global cerebral edema after subarachnoid hemorrhage: frequency, predictors, and impact on outcome. Stroke, 2002; $33: 1225-32$

6. Teasdale GM, Drake CG, Hunt W. A universal subarachnoid hemorrhage scale: report of a committee of the World Federation of Neurosurgical Societies. J Neurol Neurosurg Psychiaty, 2008; 51:1457

7. Sabri M, Kawashima A, Ai J, Macdonald RL. Neuronal and astrocytic apoptosis after subarachnoid hemorrhage: a possible cause for poor prognosis. Brain Res, 2008; 1238:163-71
8. Sabri M, Lass E, Macdonald RL. Early Brain Injury: A Common Mechanism in Subarachnoid Hemorrhage and Global Cerebral Ischemia. Stroke Research and Treatment 2013; Page-9.

9. Suarez JI, Tarr RW, Selman WR. Aneurysmal Subarachnoid Haemorrhage. New Eng J of Med, 2006; 354:387-96

10. Suwatcharangkoon S, Meyers E, Falo C, Schmidt J. M, Sachin A, Classen J et al. Loss of consciousness at onset of subarachnoid $(\mathrm{SAH})$ as an impotent marker of early brain injury. JAMA Neurol, 2016; 73(1): 28-35

11. Hasan MN, Hoque MA, Rahman KM, Hoque MH, Amin MR, Haque $M$, et al. Clinical and digital subtraction angiographic (DSA) evaluation of patients of subarachnoid haemorrhage (SAH) in a tertiary level hospital. Bangladesh Med J, 2015; 44(3):125-29 12. Islam $\mathrm{M}$, Chowdhury $\mathrm{AH}$, Chowdhury MSJH, Islam $\mathrm{MN}$, Nayeem A, Khan SU. Comparative study of computed tomography and digital subtraction angiography in evaluation of aneurysmal subarachnoid hemorrhage. J Dhaka Med Coll, 2013; 22(2): 195-200

13. Linn FHH, Rinkel GJE, Algra A, van Gijn J. Headache characteristics in subarachnoid haemorrhage and benign thunderclap headache. Journal of Neurology Neurosurgery Psychiatry, 2008; 65:791-93

14. Al-Shahi R, White PM, Davenport RJ, Lindsay KW. Subarachnoid haemorrhage. BMJ, 2006; 333:235-40

15. Julio Leonardo BP, de Albuquerque LAF, Dellaretti M, de Carvalho GTC, Vieira GI, Rocha MI, et al. Importance of recognizing sentinel headache. SurgNeurol Int, 2012; 3:162-5

16. Rashid A B, Wani M A, Kirmanj A R. Subarachnoid hemorrhage in Kashmir: Cause, risk factors and outcome. Asian J Neurosurg, 2011; 6(2):57-71

17. Koshy L, Easwer H.V, Premkumar S, Alapatt J. P, Pillai A. M, Nair S, et al. Risk factors for aneurysmal subarachnoid hemorrhage in an Indian population. Cerebrovasc Dis, 2010; 29:268-74

18. Ingall T, Asplund K, Mahonen M, Bonita R. A multinational comparison of subarachnoid hemorrhage epidemiology in the WHO MONICA stroke study. Stroke, 2000; 31:1054-61.

19. Rothwell PM, Coull AJ, Giles MF, Howard SC, Silver LE, Bull LM et al. Change in stroke incidence, mortality, case-fatality, severity, and risk factors in Oxfordshire, UK from 1981 to 2004 (Oxford Vascular Study). Lancet, 2004; 363:1925-33.

20. Mayer S.A, Kreiter K.T, Copeland D, Bernardini G.L, Bates J.E. Peery S, et al. Global and domain specific cognitive impairment and outcome after subarachnoid hemorrhage. Neurology 2002; 59:1750- 58

21. Mendes Ribeiro J.A, Sofia Pereira, Ayres Basto M and Celso Pontes. Loss of consciousness at ictus what does it mean in spontaneous subarachnoid hemorrhage? Acta Medica Portuguesa 1998:11:1085-90

22. Takahashi S, Akiyama $\mathrm{T}$, Horiguchi $\mathrm{T}$ et al. Loss of consciousness at ictus and/or poor World Federation of Neurosurgical Societies grade on admission reflects the impact of EBI and predicts poor outcome in patients with SAH. Surgical Neurology International 2020;11:40. 